\title{
Age differences in the relationship between threatening and coping mechanisms and preventive behaviors in the time of COVID-19 in the United States: Protection Motivation Theory
}

\author{
Jung Ki Kim, Eileen M. Crimmins \\ Davis School of Gerontology, University of Southern California, Los Angeles, CA, USA
}

\begin{abstract}
It is important to understand the factors motivating people to adopt recommended behavioral changes in response to the coronavirus disease 2019 (COVID-19) pandemic, and how they differ for younger and older adults. Using a nationally representative sample from the Understanding America Study (3/10-3/31/2020), we assessed how four cognitive mediators affected uptake of protective activities for younger (aged 18-34) and older adults (aged 65+) during the beginning of the COVID-19 pandemic. Confirmatory factor analysis based on Protective Motivation Theory demonstrated associations between our observed variables and the latent constructs: perceived severity and susceptibility, and response efficacy and

Correspondence: Jung Ki Kim, Davis School of Gerontology, University of Southern California, Los Angeles, CA 90089-0191, USA. Tel.: +1.213.740.0794.

E-mail: jungk@usc.edu

Citation: Kim J. K., \& Crimmins E. M. (2020). Age differences in the relationship between threatening and coping mechanisms and preventive behaviors in the time of COVID-19 in the United States: Protection Motivation Theory. Research in Psychotherapy: Psychopathology, Process and Outcome, 23(3), 239-246. doi: 10.4081/ripppo.2020.485

Acknowledgments: the project described in this paper relies on data from survey(s) administered by the Understanding America Study, which is maintained by the Center for Economic and Social Research (CESR) at the University of Southern California. The self-efficacy. Among younger adults, coping appraisal such as perceptions of effectiveness of behaviors in protecting them from coronavirus and belief in their ability to perform recommended changes led them to adopt preventive behaviors; for older people, threat appraisal such as perception of severity was associated with behavioral responses. Younger people may rely more on their assessment of coping resources and effectiveness in their response to COVID-19; while older people base their behavioral responses on their perception of the severity of the situation, which they appraise using information from media and the severity of the epidemic in their state of residence. Different strategies are required to motivate older and younger people to adopt behavioral modifications, which are critical in reducing further spread of COVID-19.
\end{abstract} collection of the UAS COVID-19 tracking data is supported in part by the Bill \& Melinda Gates Foundation and by grant U01AG054580 from the National Institute on Aging. The content of this paper is solely the responsibility of the authors and does not necessarily represent the official views of USC, UAS or the Bill \& Melinda Gates Foundation.

Funding: this work was supported by National Institute on Aging (NIA P30 AG17265).

Contributions: JKK, conceptualization, statistical analysis, initial writing, revision; EMC, revision, funding acquisition.

Conflict of interests: the authors have no conflict of interest to declare.

Human Subject Approval: USC IRB \#: UP-20-00554

Received for publication: 8 August 2020.

Revision received: 15 November 2020.

Accepted for publication: 27 November 2020.

This work is licensed under a Creative Commons Attribution NonCommercial 4.0 License (CC BY-NC 4.0).

${ }^{\circ}$ Copyright: the Author(s), 2020

Licensee PAGEPress, Italy

Research in Psychotherapy:

Psychopathology, Process and Outcome 2020; 23:239-246

doi:10.4081/ripppo.2020.485
Key words: COVID-19; protection motivation theory; behavioral change; age difference.

\section{Introduction}

While future outbreaks and the course of the pandemic are evaluated and predicted by epidemiological models, understanding people's behavioral modifications in response to the pandemic needs a more holistic approach based on the social and behavioral sciences (Ferguson, 2007; Van Bavel et al., 2020). People change their behaviors when they are motivated to do so either by internal or external forces. The coronavirus disease 2019 (COVID-19) pandemic is an external force encouraging change in people's behaviors. It is important to understand how people adopt behavioral changes in response to public health recommendations to reduce further spread of COVID-19.

In our recent study (Kim \& Crimmins, 2020), we found that younger and older adults reacted to recommendations for protective behaviors differently across the early months of the pandemic. Younger people acted more 
quickly than older people to adopt behavioral changes while older people adopted more behavioral changes as the pandemic progressed even though they were slower to engage in protective behaviors at the beginning of the pandemic. Given that older people have weaker immune systems and more underlying chronic conditions that can increase the severity and fatal consequences of the infection (Crimmins, 2020; Garg et al., 2020; Spiegelhalter, 2020), it is important to understand what made older and younger people react differently in adopting behavioral changes in the beginning of the pandemic.

Protection Motivation Theory (PMT) provides a useful theoretical framework to explain the paths that lead people to change behaviors in a situation where behavioral change is necessary such as in the prevention or treatment of health conditions (Plotnikoff \& Higginbotham, 2020) and in mitigating the pandemic (Abdulkareem, Augustijn, Filatova, Musial, \& Mustafa, 2020). In order for people to adopt preventive behaviors, they need to go through cognitive processes that mediate attitude change. Adapted from Rogers' revised theory (PrenticeDunn \& Rogers, 1986; Rogers, 1983; Rogers \& PrenticeDunn, 1997), the two cognitively mediating processes of threat and coping appraisal can be used to explain behavioral responses to the COVID-19 pandemic. Threat is appraised by one's perception of the severity and personal vulnerability to the pandemic, and coping is appraised by one's perception of response efficacy and self-efficacy. When people perceive that the disease is severe and they are vulnerable to it, they are motivated to follow public health recommendations. They also adopt behavioral changes when they think the behaviors will effectively protect them from the disease and when they think they have the ability to perform the behavioral modification (e.g., higher income and education levels) (Abdulkareem et al., 2020). According to the PMT, the higher perception of severity and vulnerability is and the greater expectation of effectiveness of recommended behaviors and belief in one's ability to perform those behaviors is, the more likely people will adopt preventive behaviors. This framework could be useful in explaining how people engage in preventive behaviors to follow public health recommendations in the COVID-19 crisis.

Motivated by our previous study (Kim \& Crimmins, 2020) that examined age differences in behavioral modifications to COVID-19 and how they changed over time, we now examine age difference in the mechanisms by which people are motivated to engage in COVID-19 related behavioral modifications. This study utilizes the Protection Motivation Theory (PMT) to examine how people's perceptions of health threatening information and coping appraisal motivate them to adopt recommendations for infection-mitigating behaviors at the beginning of the COVID-19 pandemic and how the paths for adopting these behaviors differ by age. We hypothesize that both threat and coping appraisals will have significant positive impact on behavioral change; however, younger people are more likely to be influenced by their coping appraisals while older people are more influenced by threatening health information. That is, for younger people, the adoption of protective behaviors is determined by their assessment of how much they can afford to practice these behaviors (e.g., do they have sufficient resources such as income and job security to support their lifestyle?) and how efficiently infection would be prevented by changing their behaviors; on the other hand, older people tend to make their decisions based on their perception of how severe the health effects of the pandemic would be as well as their perceived susceptibility. Test of this theory is based on the first wave of the nationally representative Understanding America Study (UAS)'s COVID-19 study, collected between March 10 and to March 31, 2020.

\section{Materials and Methods}

\section{Data}

Data come from the UAS which is an ongoing probability-based internet panel with a nationally representative sample of non-institutionalized persons 18 and over in the United States. At the beginning of the pandemic, a COVID-19 substudy was fielded. Recruited from UAS panel members, participants were randomly selected based on U.S. addresses, and unequal sampling probabilities were adjusted for underrepresented populations to obtain a nationally representative sample of adults (Alattar, Messel, \& Rogofsky, 2018; USC Dornsife Center for Economic and Social Research, 2020). Since the first survey on March 10, participants were asked to take a biweekly survey about COVID-19. Invitations were mostly sent by email and by postcard in a few cases, and surveys were answered online. The UAS is administered by the Center for Economic and Social Research (CESR) at the University of Southern California (USC) with support from the Social Security Administration (SSA), the National Institute on Aging (Alattar et al., 2018), and later COVID-19 substudies receive support from the Gates Foundation (The CESR Covid-19 Task Force, 2020). Detailed description of the data can be found in a recently published article (The CESR Covid-19 Task Force, 2020).

The first wave was collected between March 10 and March 31 of 2020 at the beginning of stay at home orders in parts of the United States; which is the time when people should have been adopting protective behaviors. The sample of 6932 respondents included all adult ages (ages 18 to 101); we analyzed respondents who have information on all variables of interest in two age groups $(\mathrm{N}=2694)$ : a younger group aged 18-34 $(\mathrm{N}=1284)$ and an older group aged $65+(\mathrm{N}=1410)$. In our analysis, we used the final post-stratification sample weight to align the sample with the entire U.S. adult population. The diagnosis rate of COVID-19 in the sample was about $0.1 \%$. 


\section{Measures}

Figure 1 shows the two processes characterizing people's cognitive appraisal of the threat of COVID-19 and their ability to cope with COVID-19. In turn, the threat and coping appraisals each consists of two components of the cognitive process proposed to lead to behavior changes. These four components are the four latent factors we examine in this paper.

\section{Protective behaviors}

Five protective behaviors were used to create a continuous variable of behavioral changes. These include reports on people's actions in the past seven days in order to keep themselves safe from coronavirus. People were asked to report actions that they took or decisions that they made personally: i) wore a mask or other face covering; ii) washed hands with soap or used hand sanitizers several times a day; iii) avoided contact with people who could be high-risk; iv) avoided public spaces, gatherings, or crowds; and v) avoided eating at restaurants. Each behavior was coded as (0) no, or (1) yes, and thus the summed variable ranged from 0 to 5 , with a higher value indicating taking more protective behaviors.

\section{Threat appraisal}

\section{Perceived severity}

We used two measures that indicate perceived severity of threat. First, we used the level of severity of COVID19 in the state where respondents lived at the time of the survey. The categorization of COVID-19 level in the state of residence was based on the number of cases in each state as of March 31, 2020 (CDC COVID-19 Response Team, 2020), resulting in 5 groups of states: (1) less than 500 (IA, DC, KS, NH, DE, NM, ME, VT, MT, HI, NE, WV, AK, ND, WY, SD), (2) 500-999 (AL, UT, OR, MN, KY, OK, AR, ID, RI), (3) 1,000-2,999 (CO, TN, OH, IN, MD, NC, VA, WI, MO, AZ, NV, SC, MS, (4) 3,000-6,999
(MA, FL, IL, LA, WA, PA, GA, TX, CT), and (5) 7000+ (NY, NJ, CA, MI). We used the categorization of state COVID-infection cases as a continuous variable, ranging from 1 to 5 .

Perceived severity was also indicated by the number of media sources of information people used to learn about COVID-19 in the past 7 days. While different sources of media and public health agents may deliver different messages about severity and recommended responses to the pandemic (Ash, Galletta, Hangartner, Margalit, \& Pinna, 2020; Simonov, Sacher, Dubé, \& Biswas, 2020), we assume that the more sources they accessed, the more severe they perceived the pandemic to be. The 10 sources we used include $A B C$ news, CBS news, CNN, Fox news, MSNBC news, NBC news, national newspapers such as the New York Times, Washington Post, and USA Today, local newspapers, public television and radio, and local TV news. Media use is a continuous variable, scaling from 0 to 10 .

\section{Perceived susceptibility}

Five measures were used that indicate perception of susceptibility. First, people provided their assessment to three questions on their personal likelihood of getting the infection, dying and being quarantined in the next 3 months. Responses scaled from 0 to 100, with 100 indicating the highest chance.

Psychological distress provides another indicator of vulnerability. The four-question scale from the Patient Health Questionnaire-4 (PHQ-4) was used as a briefscreening tool to assess the respondents' level of psychological distress. This scale was developed with two-item screeners for depression and another two items for anxiety to constitute the Patient Health Questionnaire for Depression and Anxiety (PHQ-4) (Kroenke, Spitzer, Williams, $\&$ Lowe 2009). The questions asked the number of days a respondent was: i) feeling nervous, anxious, or on edge; ii) not able to stop or control worrying (excessive worry-

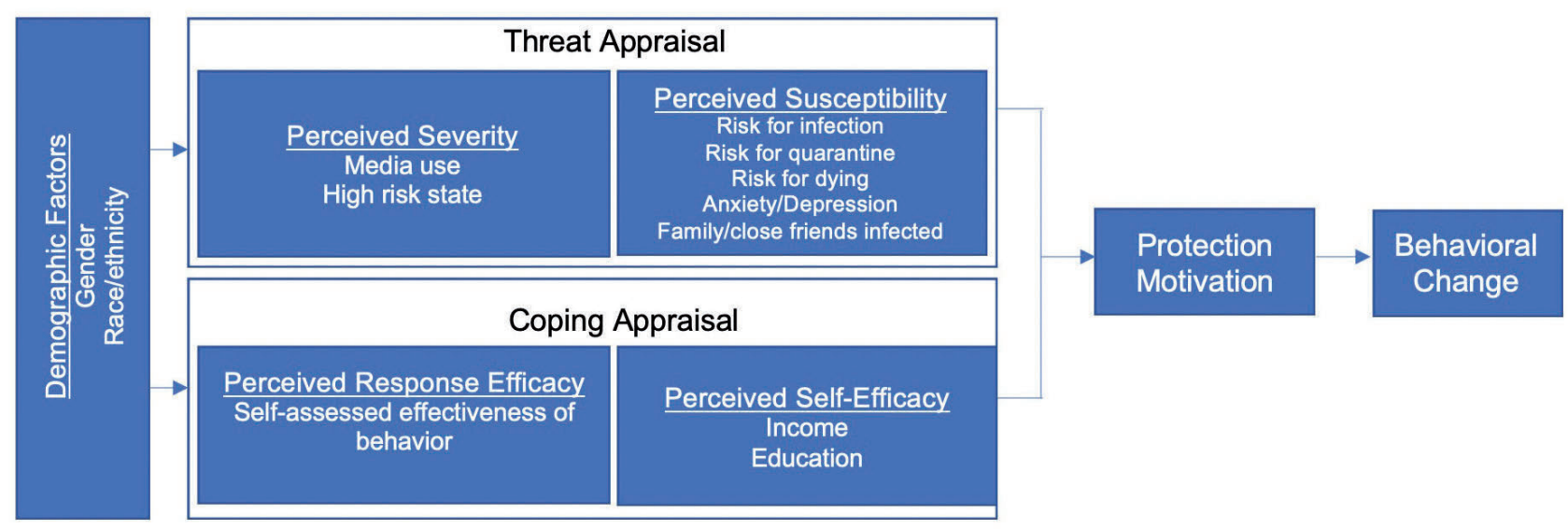

Figure 1. Behavioral change in response to COVID-19: protection motivation theory. Adapted from Rogers (1983) and Abdulkareem et al. (2020). 
ing); iii) feeling down, depressed or hopeless; and iv) having little interest or pleasure in doing things in the past two weeks. The responses were (0) not at all, (1) several days, (2) more than half the days, and (3) nearly every day. The answers were summed for a total score of psychological distress (0-12), with a higher score indicating a greater level of psychological distress. Finally, we used the number of family members or close friends who they think have been infected by coronavirus as an additional indicator of feelings of susceptibility.

\section{Coping appraisal}

\section{Perceived response efficacy}

Response efficacy was measured by the respondent's assessments of the effectiveness of the following actions for avoiding coronavirus: wearing a face mask, washing hands frequently, avoiding public places, avoiding contact with high-risk people, and avoiding eating at a restaurant. Responses were (1) extremely ineffective, (2) somewhat ineffective, (3) unsure, (4) somewhat effective, and (5) extremely effective. The summed score of assessment of effectiveness ranged from 5 to 25 , with a higher score indicating higher perception of efficacy.

\section{Perceived self-efficacy}

Household income per person and education were used to indicate personal self-efficacy. Both education and per person household income had continuous values. The midpoint of the income in the original 16 categories of household income was assigned to create the continuous measure of household income, which was divided by the number of people in the household to estimate household income per person. Education was coded as a continuous variable from 1 to 16 : (1) less than $1^{\text {st }}$ grade, (2) $1-4^{\text {th }}$ grade, (3) $5-6^{\text {th }}$ grade, (4) $7-8^{\text {th }}$ grade, (5) $9^{\text {th }}$ grade, (6) $10^{\text {th }}$ grade, (7) $11^{\text {th }}$ grade, (8) $12^{\text {th }}$ grade with no diploma, (9) high school graduate or GED, (10) some college, (11) associate college degree - occupation/vocational program, (12) associate college degree - academic program, (13) bachelor's degree, (14) master's degree, (15) professional school degree, and (16) doctorate degree.

Additional social and demographic status measures that might affect people's appraisal of threat and coping were added in the analysis. These included gender, race/ethnicity, living arrangement measured by whether a respondent lived alone or with someone else, and employment status measured by currently working, previously worked but not currently, or previously unemployed. We ran regression analyses to see the relationship between taking protective behaviors and each variable proposed in this study with these four sociodemographic measures. We also examined correlations among these variables. Being female was negatively related to household income per person and positively to psychological distress, and being a member of a racial/ethnic minority including blacks, Hispanics, Asians and all others was related to lower household income per person and state of residence with more cases of infection. Given these relationships, we included two demographic variables, gender and race/ethnicity, as background information related to observed variables in our path models.

\section{Data analysis}

We conducted path analysis using structural equation modeling. Four latent variables were developed based on the PMT framework. We first conducted confirmatory factor analysis to verify that our observed variables and the proposed latent constructs based on the PMT were associated. We tested whether the proposed model provided an adequate fit to the data. We checked three main model fit indices including the Comparative Fit Index (CFI) which is equal to the discrepancy function adjusted for sample size, and the Root Mean Square Error of Approximation (RMSEA), which indicates the amount of unexplained or residual variance, and the chi-square test, and two additional model fits (Non-normed index (NNI) and Bentler-Bonett Normed Fit Index (NFI)). The paths were estimated separately for younger adults (ages 18 to 34) and older adults (ages 65 and over) in order to evaluate age differences.

\section{Results}

Table 1 shows that younger and older age groups were quite different from each other in their adoption of behavioral changes and mediating factors. Younger people engaged in more preventive behaviors than older people (2.62 vs 2.41, $\mathrm{P}<0.05$ ). While younger people tended to perceive higher risk for infection and quarantine, older people perceived higher risk for dying. Younger people had higher level of psychological distress and had more infected family or close friends than older people did. About $62 \%$ of younger people were female while about $41 \%$ were among older people. The proportion who were members of racial/ethnic minorities was lower among older people (18.7\% compared to $45.2 \%$ among younger people, $\mathrm{P}<0.05$ ). The distribution of the states and years of education was similar for the two age groups.

Confirmatory factor analysis was done first to determine the factor structure of our observed variables and the latent constructs. We proposed four latent constructs with perceived severity and perceived susceptibility defined as threat appraisal (threat appraisal 1 and threat appraisal 2) and perceived response efficacy and perceived self-efficacy as coping mechanisms (coping appraisal 1 and coping appraisal 2) (Table 1). The model fit indicators confirmed that our model was a good fit. RMSEA was 0.0516 , which met the criteria of 0.06 or less $(\mathrm{Hu} \&$ Bentler, 1999) and CFI (0.9250), NNI (0.8835) and NFI $(0.9159)$ values also met or were close to the criteria $(0.9$ 
or larger) for acceptable model fit (Hu \& Bentler, 1999). On the other hand, the chi-square value was significant (236.98, $\mathrm{P}<0.0001$ ), which does not indicate similarity between the expected and observed covariance matrices, indicating unacceptable model fit. However, this is almost always the case where the sample size is large and other indices may be more reliable. Since four fit statistics indicated acceptable or close to acceptable fit, we conclude that this analysis confirmed the proposed factor structure in our study is acceptable as proposed.

Based on this confirmed model with background factors of gender and race/ethnicity, Figures 2 and 3 present the path models with significant standardized parameter estimates (F tests, $* \mathrm{P}<0.05$ ). The four latent factors of threat and coping appraisals with their measurement indicators, gender and race/ethnicity were evaluated in this model. The arrows in the diagrams represent the direction of the structural relations proposed to exist among variables and constructs. The thicker arrows indicate signification relationships between a latent construct and the outcome, behavioral change. Among younger people (Figure 2), coping appraisal had significant influence on pandemic mitigating behaviors. All parameter estimates were significant at the 0.05 level. While a higher level of belief in effectiveness of preventive behaviors had a positive influence on adopting behaviors (coping appraisal 1) $(\mathrm{SE} b=0.752, \mathrm{p}<0.05)$, higher education and income (coping appraisal 2) had negative influences on adopting behavioral changes ( $\mathrm{SE} b=-0.142, \mathrm{P}<0.05$ ). This indi- cates that the more effective the preventive behaviors were perceived to be and the lower the levels of income and education were, the more protective behaviors young people took. On the other hand, there was no significant path from threat appraisals to the adoption of preventive behaviors among younger people.

For older people, one of the two threat appraisals (threat appraisal 1) was related to behavioral adoption $\left(\mathrm{SE} \_\mathrm{b}=0.385, \mathrm{P}<0.05\right)$. The more media sources people used to get information about COVID-19 and living in states with more cases of COVID-19 infections were associated with adopting more protective behaviors. However, coping appraisals did not show any significant path to adopting infection-mitigating behaviors among older people.

\section{Discussion}

We examined how people make behavioral changes in response to the pandemic using a nationally representative sample of the U.S. population at younger and older ages. We evaluated paths leading to adoption of protective behaviors at the beginning of the COVID-19 pandemic. Specifically, we adapted Rogers' social cognitive model of Protection Motivation Theory (PMT) to examine how threat and coping appraisal processes were related to protective behaviors engaged in when faced with the COVID-19 pandemic, and how the process differed for

Table 1. Description of the Sample by Age, Weighted $(\mathrm{N}=2,694)$, Wave $1(3 / 10 / 20-3 / 31 / 20)$.

\begin{tabular}{|c|c|c|c|}
\hline & $\begin{array}{c}\text { Ages 18-34 } \\
(\mathrm{N}=1284) \\
\text { Mean (SD) or \% }\end{array}$ & $\begin{array}{c}\text { Ages 65+ } \\
(\mathrm{N}=1410) \\
\text { Mean (SD) or \% }\end{array}$ & Range \\
\hline Behavioral changes & $2.62(1.59)$ & $2.41 *(1.33)$ & $0-5$ \\
\hline \multicolumn{4}{|l|}{ Threat appraisal } \\
\hline $\begin{array}{l}\text { Threat appraisal 1: Perceived susceptibility } \\
\text { COVID-19 cases in state of residence } \\
\text { Number of media sources used to learn about COVID-19 }\end{array}$ & $\begin{array}{l}3.47(1.29) \\
4.02(3.65)\end{array}$ & $\begin{array}{l}3.47(1.16) \\
4.53 *(2.67)\end{array}$ & $\begin{array}{c}1-5 \\
0-10\end{array}$ \\
\hline $\begin{array}{l}\text { Threat appraisal 2: Perceived severity } \\
\text { Risk for infection } \\
\text { Risk for dying } \\
\text { Risk for quarantine } \\
\text { Psychological distress } \\
\text { Number of infected family/close friends }\end{array}$ & $\begin{array}{c}25.15(26.92) \\
11.13(19.53) \\
25.10(31.16) \\
2.66(3.41) \\
0.28(2.53) \\
\end{array}$ & $\begin{array}{c}17.88 *(19.40) \\
23.12 *(26.24) \\
17.87 *(21.83) \\
1.25 *(2.05) \\
0.10 *(1.00) \\
\end{array}$ & $\begin{array}{c}0-100 \\
0-100 \\
0-100 \\
0-12 \\
0-100\end{array}$ \\
\hline \multicolumn{4}{|l|}{ Coping appraisal } \\
\hline $\begin{array}{l}\text { Coping appraisal 1: Perceived response efficacy } \\
\text { Self-assessed effectiveness of protective behaviors }\end{array}$ & $20.46(4.10)$ & $20.07 *(3.90)$ & $5-25$ \\
\hline $\begin{array}{l}\text { Coping appraisal 2: Perceived self-efficacy } \\
\text { \$ Household income per person } \\
\text { Education }\end{array}$ & $\begin{array}{c}24,861(27,252) \\
10.77(2.53)\end{array}$ & $\begin{array}{c}34,494 *(25,345) \\
10.80(2.57)\end{array}$ & $\begin{array}{c}357-175,000 \\
1-16\end{array}$ \\
\hline \multicolumn{4}{|l|}{ Sociodemographic factors } \\
\hline$\%$ Female & $62.47 \%$ & $40.89 \% *$ & \\
\hline$\%$ Racial/ethnic minority & $45.15 \%$ & $18.70 \% *$ & \\
\hline
\end{tabular}


younger and older adults. Our results suggest that PMT provides an appropriate theoretical framework and useful insights to better understand people's motivations for adopting behavioral modifications in this pandemic. While some factors examined in this study might be more relevant to the United States such as race/ethnicity and income/education given the different racial demographic composition and social structure of societies, we believe that the results based on the PMT model in our study are applicable to most middle and high income countries in the current pandemic situation.

While not all four cognitive mediators had significant associations with taking protective behaviors for younger and older adults, our findings showed that the paths differed for younger and older adults. For older people, perceived severity of COVID-19 was positively related to the adoption of preventive behaviors; for younger people, perceived response efficacy was positively and self-efficacy, as indexed by income and education, was negatively related. While those with higher income and a more secure job represented by higher levels of education, may be able to afford changing behaviors more than those with fewer resources, those with lower income and lower levels of education may be exposed to higher risks of infection due to their job which may not be able to be performed at home and require more frequent contact of people outside the household. Thus, they may be more alert to the value of social distancing and preventive behaviors, leading them to mitigate their behaviors.
Younger people, who are generally healthier and less at risk for severe consequences of COVID-19 than older people, tend to act based on their perception of their ability to deal with the pandemic threat. If they think their actions will be efficacious, they take action (Witte \& Allen, 2000). On the other hand, older people appear to rely more on risk assessment based on the information they get from the media and on the conditions in their area of residence. While not uniform in terms of presentation of the severity and the future COVID-19 outlook, the media's focus is often on the number of COVID-19 positive cases and the death toll nationally and in local and state areas and is less focused on reporting recovery and mild or asymptomatic cases (Van Bavel et al., 2020). Older people who believe their health to be worse may be more sensitive to reported risks, which would lead them to adopt preventive behaviors.

This difference between younger and older people in the pathways to engaging in preventive behaviors suggests that different intervention strategies need to be implemented for different age groups. For younger people, it is important to educate them on the importance and effectiveness of pandemic mitigating behaviors. For example, younger people need to be consistently reminded of the effectiveness of social distancing, wearing a mask and washing hands frequently. They may be more likely to adopt behavioral modifications when they actually see the benefits of those behaviors, leading to reducing the spread of the virus and lowering death tolls (Johnson, Dawes, Fowler,

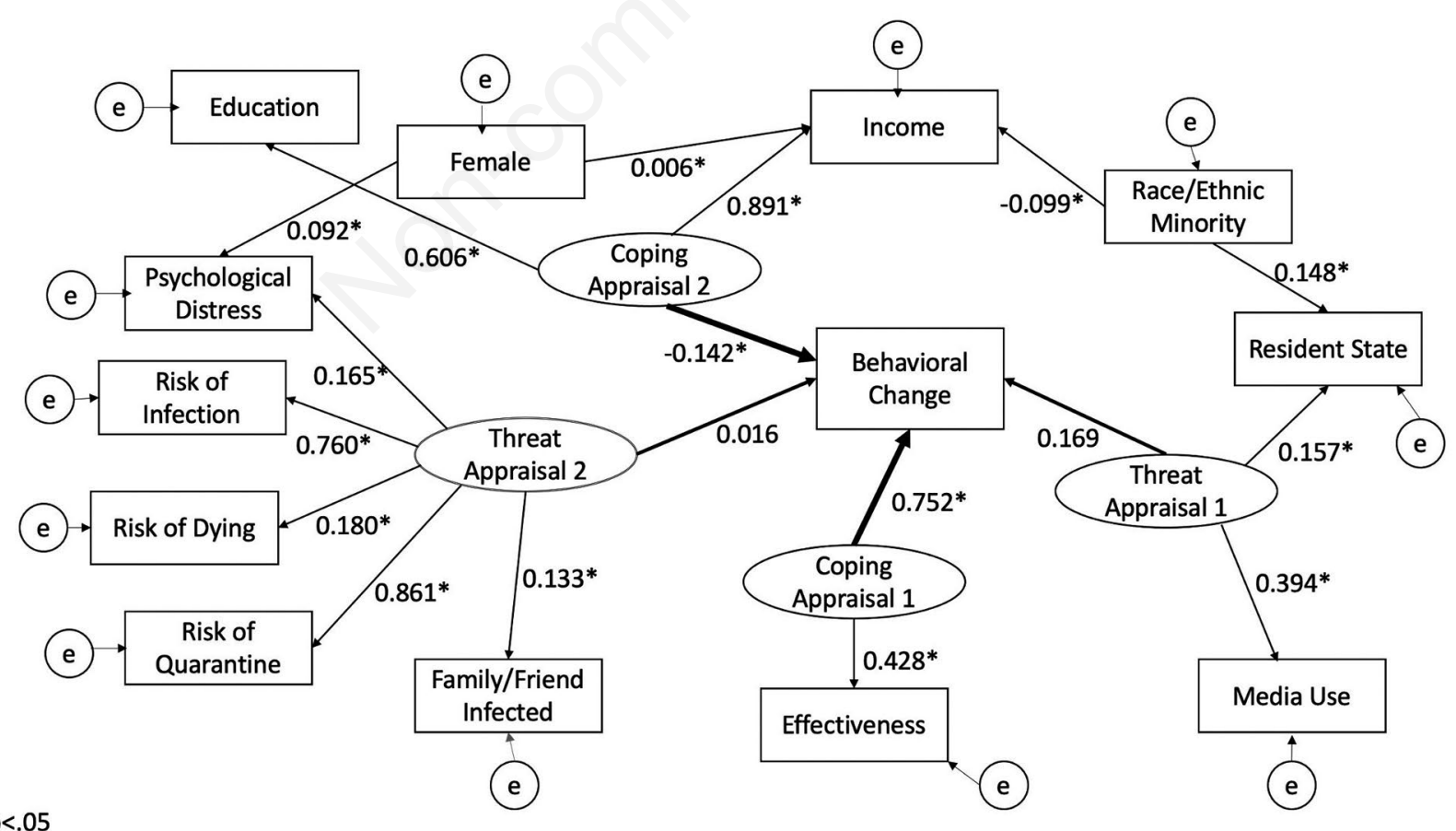

Threat Appraisal 1 (Perceived severity); Threat Appraisal 2 (Perceived susceptibility); Coping Appraisal 1 (Perceived response efficacy); Coping Appraisal 2 (Perceived self-efficacy)

Figure 2. Path model of threat and coping appraisals on behavior change in COVID-19 pandemic: ages 18-34. 
\& Smirnov, 2020). Psychotherapists who work with younger people on issues related to stress and mental health in this pandemic need to encourage preventive behaviors, showing them how behavioral changes can prevent infection, reduce the spread of the virus, and protect themselves and their families. On the other hand, for older people, based on our findings on the role of media exposure and the number of cases in the state of their residence, which is also transmitted to individuals through media exposure, local governments and county and city public health agencies can more effectively promote adopting pandemic mitigating behaviors to older persons through local news media and social media. Psychotherapists who work with older people should provide them with accurate factual information on the status of COVID-19 cases and potential for infection with adverse outcomes in their local area to help them undertake actions based on facts, not based on unwarranted anxiety or complacency.

We note that while we use available measures to construct latent constructs, some latent constructs may not be as well-measured as others. For example, we used two measures, education and income, to operationalize perceived self-efficacy. Previous studies, examining the relationship between self-efficacy and health management/health behaviors, have employed a variety of indicators of self-efficacy including disease-specific measures (Walker et al., 2020) as well as indirect measures such as socioeconomic status (Abdulkareem et al., 2020). While more direct self-efficacy measures linked to an individual's ability to successfully enact behavioral changes relevant to COVID-19 (e.g., level of confidence that they can properly quarantine themselves at home without depleting needed resources) would be ideal, we do not have such measures in the data. Thus, we used more indirect but commonly used measures of education and income to indicate self-efficacy (Abdulkareem et al., 2020). The strong positive relationships of socioeconomic status measured by income and education to self-efficacy reported in previous studies (Hankonen, Absetz, Haukkala, \& Uutela, 2009; Walker et al., 2020) justify the use of income and education in this way. This may be particularly true in the United States where there is inequality across race/ethnic and socioeconomic groups in access to many types of resources.

In sum, understanding how engaging in protective behaviors varies by age and how specific factors mediate the paths differentially for younger and older adults can help to design public health pandemic control strategies. More research is needed on how to best educate and motivate younger and older people to adopt behavioral modification to protect themselves and others.

\section{Conclusions}

Younger and older adults in the United States had different paths that lead to adopting protective behaviors in the beginning of the COVID-19 pandemic. Younger peo-

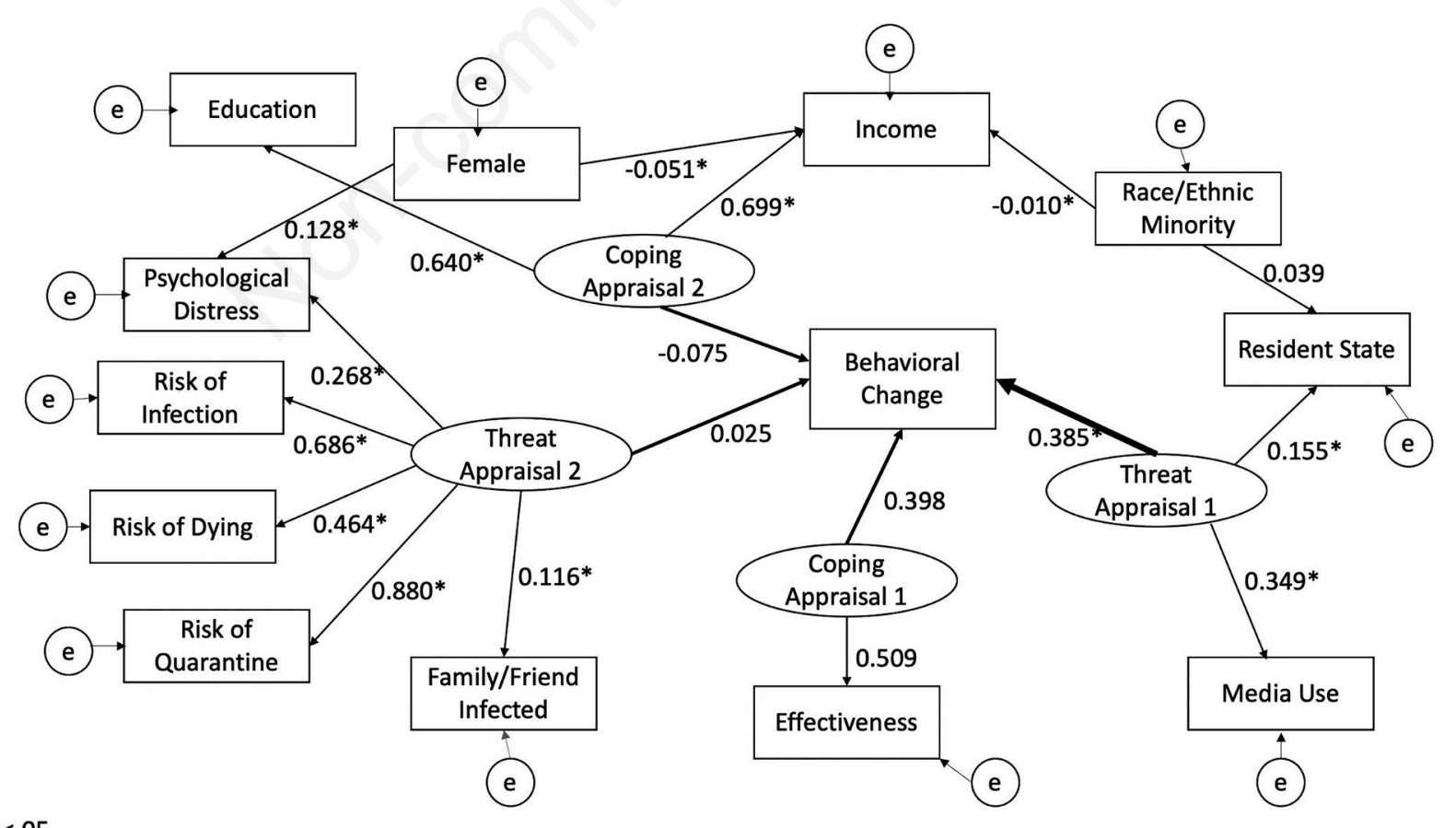

$* p<.05$

Threat Appraisal 1 (Perceived severity); Threat Appraisal 2 (Perceived susceptibility); Coping Appraisal 1 (Perceived response efficacy); Coping Appraisal 2 (Perceived self-efficacy)

Figure 3. Path model of threat and coping appraisals on behavior change in COVID-19 pandemic: ages 65+. 
ple's behavioral decisions were more based on their assessment of coping resources and effectiveness of their response to COVID-19. On the other hand, older people based their behavioral responses on their perception of the severity of the pandemic. Different strategies are required to motivate younger and older people to engage in behavioral modifications in order to reduce further spread of COVID-19.

\section{References}

Abdulkareem, S. A., Augustijn, E. W., Filatova, T., Musial, K., \& Mustafa, Y. T. (2020). Risk perception and behavioral change during epidemics: Comparing models of individual and collective learning. PLoS One, 15(1), e0226483. doi: https://doi.org/10.1371/journal.pone.0226483

Alattar, L., Messel, M., \& Rogofsky, C. (2018). An introduction to the Understanding America Study Internet Panel. Social Security Bulletin, 78(2), 13-28.

Ash, E., Galletta, S., Hangartner, D., Margalit, Y., \& Pinna, M. (2020, June 27). The effect of Fox News on health behavior during COVID-19. SSRN: https://ssrn.com/abstract= 3636762 or http://dx.doi.org/10.2139/ssrn.3636762

CDC COVID-19 Response Team. (2000). Geographic differences in COVID-19 cases, deaths, and incidence - United States, February 12-April 7, 2020. MMWR Morbidity and Mortality Weekly Report, 69, 465-471.

Crimmins, E. (2020). Age-related vulnerability to COVID-19: Biological, contextual and policy related factors. Public Policy and Aging Report. 30(4), 142-146. https://doi.org/10.1093/ ppar/praa023.

Ferguson, N. (2007). Capturing human behavior. Nature, 446, 733. doi: https://doi.org/10.1038/446733a

Garg, S., Kim, L., Whitaker, M., O'Halloran, A., Cummings, C., Holstein, R., Prill, M., Chai, S., Kirley, P., Alden, N., Kawasaki, B., Yousey-Hindes, K., Niccolai, L., Anderson, E., Openo, K., Weigel, A., Monroe, M., Ryan, P., Henderson, \& J., Fry, A. (2020). Hospitalization rates and characteristics of patients hospitalized with laboratory-confirmed coronavirus 2019 - COVID-NET, 14 states, March 1-30, 2020. MMWR Morbidity and Mortality Weekly Report, 69, 458-469.

Hankonen, N., Absetz, P., Haukkala, A., \& Uutela, A. (2009). Socioeconomic status and psychosocial mechanisms of lifestyle change in a type 2 diabetes prevention trial. Annals of Behavioral Medicine, 38(2),160-165.

Hu, L., \& Bentler, P. M. (1999). Cutoff criteria for fit indexes in covariance structure analysis: Conventional criteria versus new alternatives. Structural Equation Modeling, 6, 1-55. doi: https://doi.org/10.1080/10705519909540118

Johnson, T., Dawes, C., Fowler, J., \& Smirnov, O. (2020). Slowing COVID-19 transmission as a social dilemma: Lessons for government officials from interdisciplinary research on cooperation. Journal of Behavioral Public Administration, 3. doi: https://doi.org/10.30636/jbpa.31.150

Kim, J. K., \& Crimmins, E. M. (2020). How does age affect personal and social Reactions to COVID-19: results from the National Understanding America Survey. PLoS One, 15(11), e0241950. doi: https://doi.org/10.1371/journal.pone.0241950
Kroenke, K., Spitzer, R., Williams, J., \& Lowe, B. (2009). An ultra-brief screening scale for anxiety and depression: The PHQ-4. Psychosomatics, 50(6), 613-621. doi: https://doi.org/10.1016/S0033-3182(09)70864-3

Plotnikoff, R. C., \& Higginbotham, N. (2002). Protection Motivation Theory and exercise behaviour change for the prevention of heart disease in a high-risk, Australian representative community sample of adults. Psychology, Health \& Medicine, 7(1), 87-98. doi: https://doi.org/ 10.1080/13548500120101586

Prentice-Dunn, S., \& Rogers, R. W. (1986). Protection Motivation Theory and preventive health: beyond the Health Belief Model. Health Education Research, 1(3), 153-161. doi: https://doi.org/10.1093/her/1.3.153

Rogers, R. W. (1983). Cognitive and physiological processes in fear appeals and attitude change: A revised Theory of Protection Motivation. In J. Cacioppo \& R. Petty (Eds.), Social Psychophysiology: A Sourcebook. (pp. 153-176). New York, NY: Guilford Press.

Rogers, R. W., \& Prentice-Dunn, S. (1997). Protection motivation theory. In D. S. Gochman (Ed.), Handbook of health behavior research 1: Personal and social determinants (pp. 113-132). New York, NY: Plenum Press.

Simonov, A., Sacher, S., Dubé, J., \& Biswas, S. (2020). The persuasive effect of Fox News: Non-compliance with social distancing during the COVID-19 pandemic. NBER working paper series, No. 27237. doi: https://10.3386/w27237

Spiegelhalter D. (2020). What are the risks of COVID? And what is meant by 'the risks of COVID'? Retrieved July 1, 2020. Available from: https://medium.com/wintoncentre/what-arethe-risks-of-covid-and-what-is-meant-by-thee-risks-of-covidc828695aea69

The CESR Covid-19 Task Force. (2020). Tracking the effect of the COVID-19 pandemic on American households. Survey Research Methods, 14(2), 179-186. doi: https://doi:10. 18148/srm/2020.v14i2.7737

USC Dornsife Center for Economic and Social Research. (2020). Understanding America Study Recruitment Protocol. Retrieved July 1, 2020. Available from: https:/uasdata. usc.edu/index.php? $\mathrm{r}=\mathrm{eNpLtDKyqi62MrFSKkhMT1WyL-}$ rYyslwwskuTcjKT9VLyk0tzU NKEksy8 NS8svzcvITU0 BqgMrzEnPhykMdgxWCUpOLSSjNLQMoVAoryS_KT83P 0CILSIKxrAZOmXCIG

Van Bavel, J. J. V., Baicker, K., Boggio, P. S., Capraro, V., Cichocka, A., Cikara, M., Crockett, M., Crum, A., Douglas, K., Druckman, J., Drury, J., Dube, O., Ellemers, N., Finkel, E., Fowler, J., Gelfand, M., Han, S., Haslam, A., Jetten, J., \& Wille R. (2020). Using social and behavioural science to support COVID-19 pandemic response. Nature Human Behaviour, 4, 460-471. doi: https://doi.org/10.1038/s41562020-0884-Z

Walker, R. J., Smalls, B. L., Hernandez-Tejada, M. A., Campbell, J. A., \& Egede, L.E. (2014). Effect of diabetes self-efficacy on glycemic control, medication adherence, self-care behaviors, and quality of life in a predominantly low-income, minority population. Ethnicity \& Disease, 24(3), 349-355.

Witte, K. \& Allen, M. A. (2000). A meta-analysis of fear appeals: implications for effective public health campaigns. Health Education \& Behavior, 27, 591-615. doi: 10.1177/ 109019810002700506 